\title{
Efficacy of ibuprofen versus lornoxicam after third molar surgery: a randomized, double-blind, crossover pilot study
}

\author{
Lustenberger, F D ; Grätz, K W ; Mutzbauer, T S
}

\begin{abstract}
PURPOSE: The aim of this study is to compare the analgesic efficacy and tolerability of a preemptive/post-surgery 4-day regimen of oral ibuprofen $400 \mathrm{mg}$ with that of lornoxicam $8 \mathrm{mg}$. METHODS: Sixteen patients received ibuprofen or lornoxicam, respectively, before and after surgery of impacted third molars in two separate appointments, in a double-blind, randomized, and crossover design. The postoperative analgesic and rescue medication consumption was recorded and pain scores were evaluated with a visual analogue scale at 2, 6, 24, 48, and $72 \mathrm{~h}$, postoperatively. RESULTS: No statistically significant differences were found between ibuprofen $400 \mathrm{mg}$ and lornoxicam $8 \mathrm{mg}$ with respect to study medication $(\mathrm{p}=0.34)$ or rescue analgesic consumption $(\mathrm{p}=0.5)$ (SUMstudy and SUMrescue). Ibuprofen: SUMstudy median 7.5 interquartile range IQR (4.25-8), 95\% CI (4.6-7.7); SUMrescue median and IQR 0, 95\% CI (-0.6-4.6). Lornoxicam: SUMstudy median 7 IQR (3.75-9), 95\% CI (7.7-4.9); SUMrescue median and IQR 0, 95\% CI (-0.7-2.7). The area under the pain intensity curve (AUC(2-72) PI) over the 4 days of investigation did not reveal significant differences between the two medications $(\mathrm{p}=0.32)$. AUC(2-72) PI ibuprofen: median 1,509.7 IQR (712.36-2,444.65); 95\% CI (1,078.7-2,156.5). AUC(2-72) PI lornoxicam: median 1,166.9 IQR (783.4-2,221.2), 95\% CI (1,032-2,130.6). Moreover, patient satisfaction and incidence of adverse events did not reveal any significant differences between treatment groups. CONCLUSION: Ibuprofen $400 \mathrm{mg}$ and lornoxicam $8 \mathrm{mg}$ were rated as equal and effective pain treatment medication after wisdom tooth surgery. In comparison, neither of the drugs provided clinical advantages nor did side effects occur more frequently after one of the analgesics.
\end{abstract}

DOI: https://doi.org/10.1007/s10006-010-0255-4

Posted at the Zurich Open Repository and Archive, University of Zurich

ZORA URL: https://doi.org/10.5167/uzh-45676

Journal Article

Published Version

Originally published at:

Lustenberger, F D; Grätz, K W; Mutzbauer, T S (2011). Efficacy of ibuprofen versus lornoxicam after third molar surgery: a randomized, double-blind, crossover pilot study. Oral and Maxillofacial Surgery, $15(1): 57-62$.

DOI: https://doi.org/10.1007/s10006-010-0255-4 


\title{
Efficacy of ibuprofen versus lornoxicam after third molar surgery: a randomized, double-blind, crossover pilot study
}

\author{
Francine D. Lustenberger • Klaus W. Grätz • \\ Till S. Mutzbauer
}

Received: 25 April 2010 /Accepted: 16 November 2010 /Published online: 1 December 2010

(C) Springer-Verlag 2010

\begin{abstract}
Purpose The aim of this study is to compare the analgesic efficacy and tolerability of a pre-emptive/post-surgery 4-day regimen of oral ibuprofen $400 \mathrm{mg}$ with that of lornoxicam $8 \mathrm{mg}$.

Methods Sixteen patients received ibuprofen or lornoxicam, respectively, before and after surgery of impacted third molars in two separate appointments, in a double-blind, randomized, and crossover design. The postoperative analgesic and rescue medication consumption was recorded and pain scores were evaluated with a visual analogue scale at 2, 6, 24, 48, and $72 \mathrm{~h}$, postoperatively.

Results No statistically significant differences were found between ibuprofen $400 \mathrm{mg}$ and lornoxicam $8 \mathrm{mg}$ with respect to study medication $(p=0.34)$ or rescue analgesic consumption $(p=0.5)$ (SUMstudy and SUMrescue). Ibuprofen: SUMstudy median 7.5 interquartile range IQR (4.25-8), 95\% CI (4.6-7.7); SUMrescue median and IQR 0, 95\% CI (-0.6-4.6). Lornoxicam: SUMstudy median 7 IQR (3.75-9), 95\% CI (7.7-4.9); SUMrescue median and IQR 0, 95\% CI $(-0.7-2.7)$. The area under the pain intensity curve $\left(\mathrm{AUC}_{2-72}\right.$ $\mathrm{PI})$ over the 4 days of investigation did not reveal significant differences between the two medications $(p=0.32)$. $\mathrm{AUC}_{2-72}$ PI ibuprofen: median 1,509.7 IQR (712.36-2,444.65); 95\% CI $(1,078.7-2,156.5) . \mathrm{AUC}_{2-72}$ PI lornoxicam: median 1,166.9 IQR (783.4-2,221.2), 95\% CI $(1,032-2,130.6)$. Moreover, patient satisfaction and incidence of adverse events did not reveal any significant differences between treatment groups.
\end{abstract}

F. D. Lustenberger $\cdot$ K. W. Grätz $\cdot$ T. S. Mutzbauer $(\bowtie)$

Department of Craniomaxillofacial Surgery,

University of Zurich Dental Center,

Tiefenhoefe 11,

8001 Zurich, Switzerland

e-mail: mutzbauer@gmail.com
Conclusion Ibuprofen $400 \mathrm{mg}$ and lornoxicam $8 \mathrm{mg}$ were rated as equal and effective pain treatment medication after wisdom tooth surgery. In comparison, neither of the drugs provided clinical advantages nor did side effects occur more frequently after one of the analgesics.

Keywords Lornoxicam · Ibuprofen · Postoperative dental pain - Wisdom tooth extraction - Third molar surgery . Randomized trial $\cdot$ Pilot study

\section{Introduction}

The removal of wisdom teeth is a common oral surgical procedure, which causes an inflammatory process expressed by the classical symptoms such as swelling, pain, and impaired function. Postoperative pain following surgical removal of mandibular third molars is a validated, well-documented and highly sensitive model to assess therapeutic relief of moderate to severe pain [1-3].

One of the drugs most frequently used in the third molar model is ibuprofen, which is often used as a control medication after oral surgery [4]. Ibuprofen, a propionic acid derivate, has a clinical heritage of more than 45 years and its safety profile has been studied extensively. It became the first non-steroidal anti-inflammatory drug (NSAID) to be approved for over-the-counter (OTC) use and compared to other NSAIDs ibuprofen is associated with the lowest risk of serious upper gastrointestinal complications $[5,6]$.

Lornoxicam, a newer NSAID from the oxicam class, is frequently used for the treatment of postoperative pain following surgical interventions. Due to its rapid onset of action and the short half-life $(4-5 \mathrm{~h})$, lornoxicam has a low potential to evoke adverse reactions and has a good gastrointestinal tolerability $[7,8]$. 
The aim of this controlled, randomized, double-blind, crossover pilot study was to compare the analgesic efficacy and tolerability of a 4-day regimen of ibuprofen $400 \mathrm{mg}$ with that of lornoxicam $8 \mathrm{mg}$ in 16 patients undergoing a bilateral wisdom tooth extraction. Particularly it was of interest which medication provides a stronger analgesic effect, a longer duration of analgesia, and a better tolerability.

\section{Patients and methods}

\section{Subjects}

After approval by the local ethics committee, males and females aged between 18 and 40 years, weight between 40 and $100 \mathrm{~kg}$, who were waiting for a surgical removal of bilateral impacted third molars (as evaluated by panoramic radiography), were identified from a waiting list at the clinic. Twenty healthy patients with ASA class I or II physical status were recruited. All subjects gave fully informed written consent prior to entering the study.

Exclusion criteria included hypersensitivity to any NSAID or aspirin, asthma, history of ulcus ventriculi or duodeni, gastrointestinal hemorrhage, inflammatory gastrointestinal diseases, cardiac, renal, or hepatic insufficiency, pregnancy, and any other clinically significant systemic illness. Furthermore, any medication (except oral contraception) within the previous 14 days disqualified patients to enter the study.

\section{Medication and blinding}

Each subject had to undergo two surgical interventions to bilaterally remove their third molars. The second surgery was performed at least 3 weeks after the first intervention. Ibuprofen (Brufen ${ }^{\circledR}$; Abbott AG, Switzerland) and lornoxicam (Xefo ${ }^{\circledR}$; Nycomed Pharma AG, Switzerland) were used as preemptive and postoperative medication. Ten subjects received ibuprofen $400 \mathrm{mg}$ before the first surgical intervention. The alternative regimen administered before the second surgical intervention was lornoxicam $8 \mathrm{mg}$. The remaining ten subjects were treated vice versa. Both medications were administered immediately before surgery and were applied for a total of 4 days if necessary. In case of pain recurrence, patients were required to remedicate with the trial drug (up to three tablets daily for each study medication). Paracetamol $500 \mathrm{mg}$ (Dafalgan ${ }^{\circledR}$; Bristol-Myers Squibb SA, Switzerland) up to eight tablets per day was supplied as rescue medication for those patients who did not achieve adequate analgesia by use of the study medication.

The allocation was randomized. Surgeon and patients were blinded regarding the medication. Blinding was conducted by the hospital pharmacy according to a list generated after block randomization.

\section{Surgery}

Each surgery was performed under local anesthesia employing $4 \%$ articaine hydrochloride with epinephrine (adrenaline) $10 \mu \mathrm{g} \mathrm{ml}^{-1}$ (Ubistesin forte ${ }^{\circledR} ; 3 \mathrm{M} \mathrm{AG}$, Switzerland). Both surgical interventions were carried out by the same surgeon according to a standardized technique including mucosal flap, bone removal, splitting the tooth if necessary, and using a cotton/iodine/vaseline drainage. If it was considered necessary to remove an ipsilateral maxillary or mandibular third molar, it was also removed in the same procedure.

Study protocol

The study protocol was split into two parts; the clinical record form and the patient record form. On the clinical part, the investigator recorded demographic and surgical data. These included age, weight, gender, types and number of teeth extracted, mean duration of surgery, amount of local anesthetic used, and the degree of difficulty of the extraction. An assessment of the surgical trauma was made and complications during surgery were charted by the surgeon on a free text field.

The patient record form evaluated pain intensity (PI), rescue and study medication consumption, and adverse events.

Immediately after the surgical intervention, patients were asked to assess their PI on the patient record form during 4 days. Postoperative pain scores were recorded on a horizontal visual analogue scale (VAS) ranging from "no pain" $(0 \mathrm{~mm}=0 \%)$ on the left end to "unbearable pain" $(100 \mathrm{~mm}=100 \%)$ on the right end. Assessments were made 2 and $6 \mathrm{~h}$ postoperatively, and the first $(24 \mathrm{~h})$, second $(48 \mathrm{~h})$, and third morning $(72 \mathrm{~h})$ after surgery at 10 o'clock. The use of study and rescue medication was recorded by the subjects on the form. The amount and the time of intake were noted. Patients were asked to record details of any adverse events they had experienced due to the study medication.

Seven days after the surgical intervention, patients were invited for a follow-up examination. The dressing and sutures were removed. Patient satisfaction and a clinical status were surveyed by the investigator on the clinical record form. Parameters to assess patient satisfaction were as follows: satisfaction with the surgical intervention, satisfaction with the duration of the analgesic effect of the trial drug, overall subjective assessment of pain relief, and degree of recommendation of the respective medication. These parameters were rated by the patients on a VAS 
ranging from "no satisfaction" $(0 \mathrm{~mm}=0 \%)$ to "complete satisfaction" (100 $\mathrm{mm}=100 \%)$.

\section{Statistics}

STATA software, version 10.1 (StataCorp, College Station, TX 77845, USA) was used for data analysis. In the first stage, possible carry-over or period effects were evaluated.

As primary efficacy parameters, the area under the pain intensity curves $\left(\mathrm{AUC}_{2-72} \mathrm{PI}\right)$ of the two medications and the total amount of analgesic and rescue medication consumption (SUMstudy/SUMrescue) over the 4 days of observation were analyzed using ANOVA.

Medians, interquartile range (IQR) as well as maxima and minima of the respective data distribution were calculated. The $95 \%$ confidence interval of the mean was calculated for the main end points.

Comparisons of the remaining distributions were made by exact Wilcoxon test matched pairs statistics using the Excel add-in Analyse-it (Analyse-It Software Ltd., Leeds, UK). Statistically significant differences between data distributions were considered at $p$ values $\leq 0.05$.

The pilot study design had been approved by a biostatistician beforehand. A sample size for further studies was calculated using nQueryAdvisor 6.0 (Statistical Solutions, Saugus MA 01906, USA)

\section{Results}

Clinical parameters and patient characteristics

An overview of the demographic and surgical data obtained is presented in Table 1.
Table 2 shows the features of the third molars extracted in the study population.

Twenty patients entered the study as intent-to-treat patients, but four were excluded from the trial due to an extended delay of readmission for the second surgery.

Sixteen patients (11 male/five female) with a mean age of 24.2 years, a mean weight of $65.8 \mathrm{~kg}$, and a mean height of $171.6 \mathrm{~cm}$ were included for the statistical analysis as perprotocol population.

Neither a carry-over effect (AUC $p=0.13$, sum of medication $p=0.22$ ) nor a period effect (AUC $p=0.4$, sum of medication $p=0.34$ ) could be found comparing the two treatment groups.

No significant inter-group differences were found according to the degree of difficulty of surgery, duration of surgery, amount of local anesthetic used, and the initial pain occurrence (defined as interval from completion of surgery to second drug administration of study medication) (Table 1).

In the lornoxicam group, three patients sustained postoperative complications. Two patients suffered a mouth antrum fistula and were treated with amoxicillin. One patient developed a dry socket without pain.

In the ibuprofen treatment arm of the study, after two surgical interventions postoperative complications were observed. One subject had to be treated with a hemostatic agent due to the lesion of a venous vessel during the surgical procedure. The other one suffered a reversible hypesthesia of the tongue after suspected compression of the lingual nerve.

Pain intensity profiles after surgery

Table 3 summarizes the pain intensity profile over the 70 $\mathrm{h}$ period following administration of ibuprofen and lornoxicam.

Table 1 Patient demography and surgical characteristics-4-day regimen of ibuprofen $400 \mathrm{mg}$ versus 4-day regimen of lornoxicam $8 \mathrm{mg}$; crossover double-blinded pilot study in 16 patients undergoing third molar surgery

\begin{tabular}{|c|c|c|c|}
\hline & Lornoxicam & Ibuprofen & $p$ value \\
\hline \multicolumn{4}{|l|}{ Patient demography } \\
\hline Gender (male/female) & \multicolumn{2}{|c|}{$11 / 5$} & \\
\hline Age (years) & \multicolumn{2}{|c|}{$23.12(21.61-26.06)$} & \\
\hline Height $(\mathrm{cm})$ & \multicolumn{2}{|c|}{$171.5(168.5-177.25)$} & \\
\hline Weight $(\mathrm{kg})$ & \multicolumn{2}{|c|}{$65.8(59.5-74.5)$} & \\
\hline \multicolumn{4}{|l|}{ Surgical characteristics } \\
\hline Injection (ml) & $4.45(2.45-5.1)$ & $4.35(2.45-5.1)$ & n.s. $(0.63)$ \\
\hline Duration of surgery (min) & $20(15-31.75)$ & $30(17.25-36.25)$ & n.s. $(0.81)$ \\
\hline \multicolumn{4}{|l|}{ Pain characteristics } \\
\hline Time until onset of pain after surgery (min) & $215(175-219.5)$ & $250(211-262.5)$ & n.s. $(0.7)$ \\
\hline
\end{tabular}

All values shown are expressed as median and interquartile range (first-third quartile) unless otherwise stated n.s. no statistically significant inter-group differences; significant inter-group differences considered at $p$ values $\leq 0.05$ 
Table 2 Surgeries performed in two study arms - 4-day regimen of ibuprofen $400 \mathrm{mg}$ versus 4 day regimen of lornoxicam $8 \mathrm{mg}$; crossover double-blinded pilot study in 16 patients undergoing third molar surgery

\begin{tabular}{lcccccc}
\hline Tooth number & 18 & 28 & 38 & 48 & $28 / 38$ & $18 / 48$ \\
\hline Ibuprofen (no. of pat.) & 2 & 3 & 3 & 0 & 4 & 4 \\
Lornoxicam (no. of pat.) & 2 & 3 & 0 & 3 & 4 & 4 \\
\hline
\end{tabular}

The overall analgesic effect of ibuprofen was similar to that of lornoxicam. No statistically significant inter-group differences in pain intensity were found in the median AUC values over the 4 days of investigation $\left(\mathrm{AUC}_{2-72} \mathrm{PI}\right)$ as shown in Table 4.

Study analgesic and rescue medication consumption

In terms of the amount of ingested study medication during the 4 days of observation (SUMstudy), there were no statistically relevant differences between ibuprofen and lornoxicam.

In both treatment groups, three patients asked for rescue medication. With regard to the amount of ingested rescue medication over time (SUMrescue) and the number of requesting patients, no significant differences between ibuprofen and lornoxicam could be found (Table 4).

\section{Tolerability}

The patients rated the severity of all adverse effects as mild to moderate. There was no significant difference between the two treatments regarding the number and types of adverse events reported. A total of two patients in the ibuprofen group and two patients in the lornoxicam group sustained adverse events.

A short-lasting nausea after drug administration was recorded from one patient in the ibuprofen and two patients in the lornoxicam group. One of these patients was treated with amoxicillin concomitantly. However, it remains unclear whether this nausea was due to the antibiotic or due to lornoxicam.

One patient reported reversible heartburn symptoms after administration of ibuprofen.

Patient satisfaction and overall assessment of the analgesic efficacy 7 days after extraction

No statistically significant differences were found between ibuprofen and lornoxicam concerning patient satisfaction with the surgical intervention $(p=0.6)$, satisfaction with the duration of analgesic effect of the trial drug $(p=0.7)$, and the overall subjective assessment of pain relief over 7 days $(p=1.0)$. Furthermore, recommendation scores did not reveal any significant differences $(p=0.5)$.

When interviewing the patients 7 days after the second intervention, seven patients out of 16 had the opinion that ibuprofen was more effective than lornoxicam. Seven were convinced that lornoxicam had a stronger effect and two patients rated the effectiveness as equal.

\section{Sample size calculation}

This pilot study already allows to estimate a sample size which is the minimum to achieve a power of $80 \%$
Table 3 Pain intensity (PI) profile over a 70-h period of observation after administration of a 4-day regimen ibuprofen $400 \mathrm{mg}$ versus a 4day regimen lornoxicam $8 \mathrm{mg}$; crossover double-blinded pilot study in
16 patients undergoing third molar surgery; assessed on a $100 \mathrm{~mm}$ VAS $[0 \mathrm{~mm}=$ no pain $(0 \%), 100 \mathrm{~mm}=$ unbearable pain $(100 \%)]$

\begin{tabular}{|c|c|c|c|c|c|c|}
\hline & $2 \mathrm{~h}$ post-OP & $6 \mathrm{~h}$ post-OP & 1st morn post-OP & 2nd morn post-OP & 3rd morn post-OP & $\mathrm{AUC}_{2-72} \mathrm{PI}$ \\
\hline \multicolumn{7}{|c|}{ PI ibuprofen } \\
\hline Max & 40.4 & 48.5 & 56.5 & 51.9 & 50 & 3,194 \\
\hline $75 \% \mathrm{Q}$ & 8.86 & 38.85 & 42.45 & 42.25 & 22.35 & $2,444.65$ \\
\hline Median & 3.3 & 18.3 & 26.2 & 22.95 & 5.9 & $1,509.7$ \\
\hline $25 \% \mathrm{Q}$ & 2.3 & 4.95 & 7 & 7.05 & 2.06 & 712.36 \\
\hline Min & 0 & 2.3 & 3.3 & 0 & 0 & 163.05 \\
\hline \multicolumn{7}{|c|}{ PI lornoxicam } \\
\hline Max & 45.7 & 54.2 & 50.4 & 76.1 & 51.4 & $3,604.2$ \\
\hline $75 \% \mathrm{Q}$ & 8.8 & 47.6 & 39.36 & 38.95 & 24.25 & $2,221.2$ \\
\hline Median & 6.6 & 28.25 & 16.85 & 15.9 & 17.6 & $1,166.9$ \\
\hline $25 \% \mathrm{Q}$ & 3.05 & 16.85 & 7.43 & 7.13 & 4.5 & 783.4 \\
\hline Min & 0.4 & 3.3 & 0.47 & 0.47 & 0.47 & 94.4 \\
\hline
\end{tabular}

Data are presented as median, first and third quartile, maximum and minimum

$A U C_{2-72} P I$ area under pain intensity curve during the 4 days of observation (2-72 $\mathrm{h}$ after surgery) 
Table 4 Primary efficacy parameters: pain intensity $\left(\mathrm{AUC}_{2-72} \mathrm{PI}\right)$ and total analgesic/rescue medication consumption (SUMstudy/SUMrescue) over the 4 days of observation-a 4-day regimen of ibuprofen $\left(\right.$ Brufen $\left.^{\circledR}\right) 400 \mathrm{mg}$ versus a 4-day regimen of lornoxicam $\left(\mathrm{Xefo}^{\circledR}\right)$
$8 \mathrm{mg}$; crossover double-blinded pilot study in 16 patients undergoing third molar surgery; PI assessed on a $100 \mathrm{~mm}$ VAS $[0 \mathrm{~mm}=$ no pain $(0 \%), 100 \mathrm{~mm}=$ unbearable pain $(100 \%)]$

\begin{tabular}{|c|c|c|c|c|c|}
\hline & Lornoxicam & 95\% CI lornoxicam & Ibuprofen & 95\% CI ibuprofen & $p$ value \\
\hline $\mathrm{AUC}_{2-72} \mathrm{PI}$ & $1,166.9(783.4-2,221.2)$ & $1,032-2,130.6$ & $1,509.7(712.36-2,444.65)$ & $1,078.7-2,156.5$ & 0.32 \\
\hline $\begin{array}{l}\text { SUMstudy analgesia } \\
\text { (no. of tablets/4 days) }\end{array}$ & $7(3.75-9)$ & $7.7-4.9$ & $7.5(4.25-8)$ & $4.6-7.7$ & 0.34 \\
\hline $\begin{array}{l}\text { SUMrescue analgesia } \\
\text { (no. of tablets } / 4 \text { days) }\end{array}$ & 0 & $-0.7-2.7$ & 0 & $-0.6-4.6$ & 0.5 \\
\hline
\end{tabular}

All values shown are expressed as median and interquartile range (first-third quartile). Statistically significant differences between data distribution were considered at $p$ values $\leq 0.05$

95\% CI 95\% confidence interval of the mean

comparing the efficacy of the pain-relieving effect of both drugs.

It is generally accepted that a pain score of $30 \%$ should be the minimum target to be achieved in a situation of pain by use of an analgesic medication. Therefore, this score was used as the basis of calculation for a drug with a low but still acceptable impact of analgesic action. As high impact, the mean value of the best action of ibuprofen/lornoxicam achieved in this study (around $0.4 \%$ ) was chosen. Considering a power of $80 \%$, nQuery Advisor software calculation revealed a minimum number of six study participants to confirm a difference between pain scores of the two drugs at a required $p$ value of 0.05 .

\section{Discussion}

In the present pilot study, pain following surgical removal of third molar teeth was used as a model to evaluate the analgesic efficacy of ibuprofen compared to lornoxicam. This pain model has been widely accepted to compare the efficacy of drugs [1]. Third molar surgery for pain studies fulfills most of the requirements of a good pain model: a predictable development of inflammation, a homogenous study population of young, healthy subjects who are able to understand the given information, and surgery performed without any concomitant medication. Furthermore, this type of surgery is localized, performed with a standardized technique, usually completed in 10 to $20 \mathrm{~min}$, and performed under local anesthesia. The age and general health of the patients ensures a minimal risk of complications resulting from the administration of the study medication [3]. In the present study, the two treatment groups were well matched concerning duration of surgery, amount of local anesthesia used, number of extracted wisdom teeth, and amount of postoperative complications.

Neither of the study medication did show convincing analgesic superiority when both drugs were given up to three times daily for 4 days with respect to analgesic efficacy, tolerability, and patient satisfaction.

Regarding the clinical efficacy parameters such as time until initial pain occurrence, duration of the analgesia, consumption of trial or rescue medication, ibuprofen and lornoxicam did not reveal statistically significant differences.

Regarding patient satisfaction and the overall assessments 7 days postoperatively, the efficacy was rated as similar. Eighty two percent in the ibuprofen group and $87 \%$ in the lornoxicam group would recommend their medication.

Lornoxicam and ibuprofen were well tolerated and only a few side effects were reported.

Considering the fact that pain scores of $30 \%$ and $0.4 \%$ may serve as edge values for calculation of an $\mathrm{AUC}_{2-72}$ between the best and a still acceptable analgesic action of a pain medication after wisdom tooth surgery, the sample size in this pilot study sufficiently allows the statement that both drugs tested may be rated as equally effective at the respective dosage.

According to the pertinent literature, the efficacy of lornoxicam has been shown for various surgical indications [9-11] as well as dental surgery $[8,12,13]$. Furthermore, it has been successfully used in the treatment of painful inflammatory musculoskeletal conditions [14].

Some trials suggest that lornoxicam is as effective as the opioid analgesics morphine, pethidine, and tramadol in relieving postoperative pain [15].

When used after oral surgery, oral lornoxicam $8 \mathrm{mg}$ was as effective as oral ketorolac $10 \mathrm{mg}$ [8], aspirin $650 \mathrm{mg}$ [13], and morphine $20 \mathrm{mg}$ [12].

Nørholt and co-workers compared intramuscular injections of lornoxicam $(4,8,16$, and $20 \mathrm{mg})$ with morphine (10 $\mathrm{mg}$ and $20 \mathrm{mg}$ ) and placebo in 252 patients with moderate to severe pain. No significant difference was detected between morphine $20 \mathrm{mg}$ and lornoxicam 8, 16, and $20 \mathrm{mg}$. However, lornoxicam was associated with a significant lower incidence of adverse events than morphine [12]. 
A systematic review of studies that examined the relative risks of gastrointestinal complications associated with different NSAIDs found ibuprofen to be the least toxic, especially at the lower end of the prescription dose range [16].

The Paracetamol, Aspirin and Ibuprofen New tolerability (PAIN) study was a blinded, randomized study investigating the tolerability of ibuprofen, aspirin, and paracetamol at OTC doses in the treatment of common types of acute pain in a total of 8,677 adults randomized to either ibuprofen $(1,200 \mathrm{mg} /$ day $)$, paracetamol ( $3 \mathrm{~g} /$ day $)$, or aspirin ( $3 \mathrm{~g} /$ day $)$ for 1-7 days. Ibuprofen was found to be of similar efficacy compared to paracetamol $(p=0.85)$. A total of $13.7 \%$ patients reported adverse events (dyspepsia, abdominal) after receiving ibuprofen. Both ibuprofen and paracetamol were significantly better tolerated than aspirin $(p=0.001)$ [17].

\section{Conclusion}

Overall, equal analgesic effects can be achieved using preemptive and post-surgical analgesic regimens of single doses of ibuprofen $400 \mathrm{mg}$ and lornoxicam $8 \mathrm{mg}$ at a maximum of three applications daily for 4 days after wisdom tooth surgery. Both non-steroidal anti-inflammatory drugs proved to be effective in the management of pain following surgical removal of impacted third molar teeth with a high grade of patient satisfaction.

Conflict of interest The authors declare that they have no conflict of interest.

\section{References}

1. Cooper SA, Beaver WT (1976) A model to evaluate mild analgesics in oral surgery outpatients. Clin Pharmacol Ther 20:241-250

2. Forbes JA (1991) Oral surgery. In: Max M, Portenoy R, Laska E (eds) Advances in pain research and therapy. Raven, New York, pp 347-374

3. Nørholt SE (1998) Treatment of acute pain following removal of mandibular third molars. Use of the dental pain model in pharmacological research and development of a comparable animal model. Int J Oral Maxillofac Surg 27(Suppl 1):1-41

4. Frame JW, Evans CR, Flaum GR, Langford R, Rout PG (1989) A comparison of ibuprofen and dihydrocodeine in relieving pain following wisdom teeth removal. Br Dent J 166:121-124

5. Henry D, Lim LL, Garcia Rodriguez LA, Perez Gutthann S, Carson JL, Griffin M et al (1996) Variability in risk of gastrointestinal complications with individual non-steroidal antiinflammatory drugs: results of a collaborative meta-analysis. BMJ 313:1563-1566

6. Doyle G, Furey S, Berlin R, Cooper S, Jayawardena S, Ashraf E et al (1999) Gastrointestinal safety and tolerance of ibuprofen at maximum over-the-counter dose. Aliment Pharmacol Ther 13:897-906

7. Balfour JA, Fitton A, Barradell LB (1996) Lornoxicam: a review of its pharmacology and therapeutic potential in the management of painful and inflammatory conditions. Drugs 51:639-657

8. Nørholt SE, Sindet-Pedersen S, Bugge C, Branebjerg PE, Ersbøll BK, Bastian HL (1995) A randomized, double-blind, placebocontrolled, dose-response study of the analgesic effect of lornoxicam after surgical removal of mandibular third molars. J Clin Pharmacol 35:606-614

9. Staunstrup H, Ovesen J, Larsen UT, Larsen UT, Elbaek K, Larsen U, Krøner K (1999) Efficacy and tolerability of lornoxicam versus tramadol in postoperative pain. J Clin Pharmacol 39:834-841

10. Rosenow DE, Albrechtsen M, Stolke D (1998) A comparison of patient-controlled analgesia with lornoxicam versus morphine in patients undergoing lumbar disc surgery. Anesth Analg 86:10451050

11. Ilisa W, Jansen M (1996) Pain control after hysterectomy: an observer-blind, randomised trial of lornoxicam versus tramadol. Br J Clin Pract 50:197-202

12. Nørholt SE, Sindet-Pedersen S, Jensen J (1996) Pain control after dental surgery: a double-blind, randomised trial of lornoxicam versus morphine. Pain 67:335-343

13. Patel A, Skelly AM, Kohn H, Preiskel HW (1991) Double-blind placebo-controlled comparison of the analgesic effects of single doses of lornoxicam and aspirin in patients with postoperative dental pain. Br Dent J 170:295-299

14. Rose P, Steinhauser C (2004) Comparison of lornoxicam and rofecoxib in patients with activated osteoarthritis (COLOR study). Clinc Drug Invest 24:227-236

15. Sapolya O, Karamanhoglu B, Memis D (2007) Analgesic effects of lornoxicam after total abdominal hysterectomy. J Opioid Manag 383:155-159

16. Henry D, McGettigan P (2003) Epidemiology overview of gastrointestinal and renal toxicity of NSAIDs. Int J Clin Pract Suppl 135:43-49

17. Moore N, Vanganse E, Le Parc J-M et al (1999) The PAIN study: paracetamol, aspirin and ibuprofen new tolerability study: a large scale, randomised clinical trial comparing the tolerability of aspirin, ibuprofen and paracetamol for short-term analgesia. Clin Drug Invest 18:89-98 